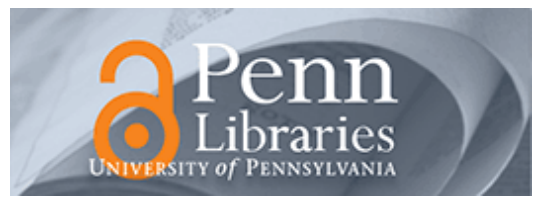

University of Pennsylvania

ScholarlyCommons

Finance Papers

Wharton Faculty Research

7-2002

\title{
On the Invariance of the Rate of Return to Convex Adjustment Costs
}

Andrew B. Abel

University of Pennsylvania

Follow this and additional works at: https://repository.upenn.edu/fnce_papers

Part of the Finance Commons, and the Finance and Financial Management Commons

\section{Recommended Citation}

Abel, A. B. (2002). On the Invariance of the Rate of Return to Convex Adjustment Costs. Review of Economic Dynamics, 5 (3), 586-601. http://dx.doi.org/10.1006/redy.2001.0158

This paper is posted at ScholarlyCommons. https://repository.upenn.edu/fnce_papers/197

For more information, please contact repository@pobox.upenn.edu. 


\title{
On the Invariance of the Rate of Return to Convex Adjustment Costs
}

\author{
Abstract \\ The modified golden rule, which relates the rate of return on capital and the growth rate of the capital \\ stock along long-run growth paths that maximize the utility of a representative infinitely lived consumer, is \\ invariant to the introduction of convex capital adjustment costs. Therefore, along balanced growth paths \\ in neoclassical optimal growth models with an exogenous long-run growth rate of capital, the rate of \\ return is invariant to the introduction of convex adjustment costs, though the capital-labor ratio is \\ reduced along such paths. In $A K$ models, convex adjustment costs reduce the growth rate and rate of \\ return on capital. Journal of Economic Literature Classification Number: E2. \\ Disciplines \\ Economics | Finance | Finance and Financial Management
}




\title{
NBER WORKING PAPER SERIES
}

ON THE INVARIANCE OF THE RATE OF RETURN TO CONVEX ADJUSTMENT COSTS

Andrew B. Abel

Working Paper 8635

http://www.nber.org/papers/w8635

\author{
NATIONAL BUREAU OF ECONOMIC RESEARCH \\ 1050 Massachusetts Avenue \\ Cambridge, MA 02138 \\ December 2001
}

This paper supercedes “The Golden Rule and Convex Adjustment Costs.” I thank Bill Dupor, Joao Gomes, Urban Jermann, Amir Yaron and the Penn Macro Lunch Group for helpful discussion, and an anonymous referee for helpful comments. The views expressed herein are those of the author and not necessarily those of the National Bureau of Economic Research.

(C) 2001 by Andrew B. Abel. All rights reserved. Short sections of text, not to exceed two paragraphs, may be quoted without explicit permission provided that full credit, including $\mathbb{C}$ notice, is given to the source. 
On the Invariance of the Rate of Return to Convex Adjustment Costs

Andrew B. Abel

NBER Working Paper No. 8635

December 2001

JEL No. E2

\begin{abstract}
The Modified Golden Rule, which relates the rate of return on capital and the growth rate of the capital stock along long-run growth paths that maximize the utility of a representative infinitely-lived consumer, is invariant to the introduction of convex capital adjustment costs. Therefore, along balanced growth paths in neoclassical optimal growth models with an exogenous long-run growth rate of capital, the rate of return is invariant to the introduction of convex adjustment costs, though the capital-labor ratio is reduced along such paths. In AK models, convex adjustment costs reduce the growth rate and rate of return on capital.
\end{abstract}

\author{
Andrew B. Abel \\ Department of Finance \\ The Wharton School of the University of Pennsylvania \\ 2315 Steinberg Hall - Dietrich Hall \\ 3620 Locust Walk \\ Philadelphia, PA 19104-6367 \\ and NBER \\ abel@wharton.upenn.edu
}


Convex adjustment costs were introduced in general equilibrium models to help smooth the behavior of aggregate investment in these models ${ }^{1}$ and to allow the equilibrium price of capital to be determined endogenously. ${ }^{2}$ Although the introduction of convex adjustment costs has interesting effects on the price and accumulation of capital in the long run, as well as in the short run, the long-run rate of return on capital is invariant to the introduction of adjustment costs in neoclassical growth models in which the utility of a representative consumer is maximized, either by a social planner or by individuals in competitive markets. Though this invariance is a robust and easily-derived result in a widely-analyzed class of neoclassical growth models, it has apparently gone unnoticed. For instance, Abel and Blanchard (1983) concluded that convex adjustment costs require a modification to the Modified Golden Rule relating the marginal product of capital and the growth rate of the economy. However, here I focus on the rate of return to capital, rather than on the marginal product of capital, and show that there is no need to modify the Modified Golden Rule relationship between the rate of return and the growth rate of the economy.

The invariance of the Modified Golden Rule relationship between the rate of return and the growth rate has several important implications. First, as noted above, in neoclassical growth models in which the long-run growth rate of the economy is exogenous, the long-run rate of return is invariant to adjustment costs, either in competitive economies with a representative consumer or in allocations chosen by a social planner. Second, by letting the social discount rate equal zero, the Modified Golden Rule delivers the Golden Rule. Therefore, the introduction of convex adjustment costs has no effect on the equality of the rate of return and the growth rate of capital in the Golden Rule. Third, Phelps $(1961,1965)$ and Swan (1964) have shown that in neoclassical growth models without adjustment costs, the Golden Rule is characterized by the equality of aggregate consumption and aggregate wage income. I show that this characterization also holds in the presence of convex adjustment costs, and I go on to generalize this result to characterize optimal consumption when the social discount rate is positive and there are convex adjustment costs: in the absence of productivity growth, aggregate consumption equals aggregate wage income plus the value of the end-ofperiod capital stock multiplied by the discount rate. Fourth, in endogenous

\footnotetext{
${ }^{1}$ See, for example, Abel and Blanchard (1983) and Baxter and Crucini (1993).

${ }^{2}$ See, for example, Basu (1987), Jermann (1998), and Abel (2000).
} 
growth models of the $A K$ variety, the introduction of convex adjustment costs reduces the rate of return on capital in the Modified Golden Rule. I will show that the Modified Golden Rule relationship between the rate of return and the growth rate of capital in $A K$ models is invariant to convex adjustment costs. However, the introduction of convex adjustment costs reduces the long-run growth rate of the capital stock, and, according to the unchanged Modified Golden Rule relationship, also reduces the rate of return.

I describe the production-cum-adjustment-cost technology in Section 1 and then express the price of capital and the rate of return on capital in terms of the technology. In Section 2, I define two notions of growth paths to describe the long-run behavior of the economy, and I show that the price of capital and the rate of return on capital are constant along these paths. I also derive an expression for aggregate consumption along these paths. I introduce intertemporal optimization in Section 3 and derive the Modified Golden Rule and various corollaries, including the invariance of the rate of return to the introduction of convex adjustment costs in neoclassical growth models. In Section 4, I show that the introduction of convex adjustment costs reduces (or leaves unchanged, in a limiting case) the capital-labor ratio along balanced growth paths in neoclassical growth models. In $A K$ models, the introduction of convex adjustment costs reduces the long-run growth rate of the capital stock and reduces the Modified Golden Rule rate of return. I present concluding remarks in Section 5.

\section{The Aggregate Production Possibilities Fron- tier}

Consider the aggregate production possibilities frontier relating aggregate consumption in period $t, C_{t}$, and the aggregate capital stock carried into period $t+1, K_{t+1}$. Specifically, consider

$$
C_{t}=J\left(K_{t}, K_{t+1}, A_{t} N_{t}\right)
$$

where $K_{t}$ is the aggregate capital stock at the beginning of period $t, N_{t}$ is both the number of people and the aggregate amount of labor used in production in period $t$, and $A_{t}$ is an index of labor-augmenting technical progress. As in Lucas $(1967)^{3}$, assume that $J\left(K_{t}, K_{t+1}, A_{t} N_{t}\right)$ is twice differentiable,

\footnotetext{
${ }^{3}$ Equation (1) is a discrete-time adaptation of the continuous-time specification in Lucas (1967).
} 
homogeneous of degree one in its three arguments $K_{t}, K_{t+1}$, and $A_{t} N_{t}$, and is (weakly) concave in these arguments. Assume that $\lim _{K_{t} \rightarrow 0} J_{1}\left(K_{t}, K_{t+1}, A_{t} N_{t}\right)=$ $\infty, \lim _{K_{t} \rightarrow \infty} J_{1}\left(K_{t}, K_{t+1}, A_{t} N_{t}\right) \leq 0$ and $J_{3}\left(K_{t}, K_{t+1}, A_{t} N_{t}\right) \geq 0$, where $J_{i}\left(K_{t}, K_{t+1}, A_{t} N_{t}\right)$ is the partial derivative of $J\left(K_{t}, K_{t+1}, A_{t} N_{t}\right)$ with respect to its $i-t h$ argument.

In the absence of convex adjustment costs, $J_{2}\left(K_{t}, K_{t+1}, A_{t} N_{t}\right) \equiv-1$ because $K_{t+1}$ can be increased by one unit simply by reducing current consumption by one unit. To illustrate the impact of convex adjustment costs on $J_{2}\left(K_{t}, K_{t+1}, A_{t} N_{t}\right)$, consider the widely-used case in which adjustment costs are independent of labor and are additively separable from the production function $^{4}$

$$
J\left(K_{t}, K_{t+1}, A_{t} N_{t}\right) \equiv F\left(K_{t}, A_{t} N_{t}\right)-\left[K_{t+1}-(1-\delta) K_{t}+\Psi\left(K_{t}, K_{t+1}\right)\right]
$$

where the production function $F\left(K_{t}, A_{t} N_{t}\right)$ is (weakly) increasing, (weakly) concave, and linearly homogeneous in $K_{t}$ and $A_{t} N_{t}$. Convex adjustment costs are represented by $\Psi\left(K_{t}, K_{t+1}\right) \geq 0$, which is twice differentiable and linearly homogeneous in $K_{t}$ and $K_{t+1}$, convex in $K_{t+1}$, and attains its minimum value of zero when $K_{t+1}=\phi K_{t}$ for some positive constant $\phi$.

Figure 1 illustrates a convex adjustment cost function for a given value of $K_{t}$. In formulations in which the convex adjustment cost function takes on its minimum value of zero when gross investment is zero, the parameter $\phi$ equals $1-\delta$, where $0 \leq \delta \leq 1$ is the depreciation rate of capital per period. ${ }^{5}$ In formulations in which the convex adjustment cost takes on its minimum value of zero when net investment is zero, the parameter $\phi$ equals $1 .{ }^{6}$ In

\footnotetext{
${ }^{4}$ Abel and Blanchard (1983), Baxter and Crucini (1993), Baxter and Jermann (1999), Blanchard and Fischer (1989), Gould (1968), Jermann (1998), and Treadway (1969) assume that the adjustment cost function is additively separable from the production function.

${ }^{5}$ Gould (1968) specifies the adjustment cost as a function of gross investment, and the adjustment cost equals zero when gross investment is zero. However, Gould's adjustment cost function is not linearly homogeneous in $K_{t}$ and $K_{t+1}$. Abel and Blanchard (1983) specify a convex adjustment cost function that is linearly homogenous in investment and the capital stock in continuous time (and thus would be linearly homogeneous in $K_{t}$ and $K_{t+1}$ in a discrete-time version). In that specification, the adjustment cost is zero when gross investment is zero.

${ }^{6}$ Treadway (1969) specifies the adjustment cost as a function of net investment, and this function attains its minimum value when net investment is zero. However, Treadway's adjustment cost function is not linearly homogeneous in $K_{t}$ and $K_{t+1}$. Blanchard and Fischer $(1989$, p. 59) specify a convex adjustment cost function that is linearly homoge-
} 
some formulations, $\phi>1$. For instance, Baxter and Crucini (1993), Baxter and Jermann (1999), and Jermann (1998) assume that $\phi=G_{K}$, where $G_{K}$ is the gross growth rate of capital, $\frac{K t+1}{K t}$, along a balanced growth path. In a growing economy, $\phi=G_{K}>1$.

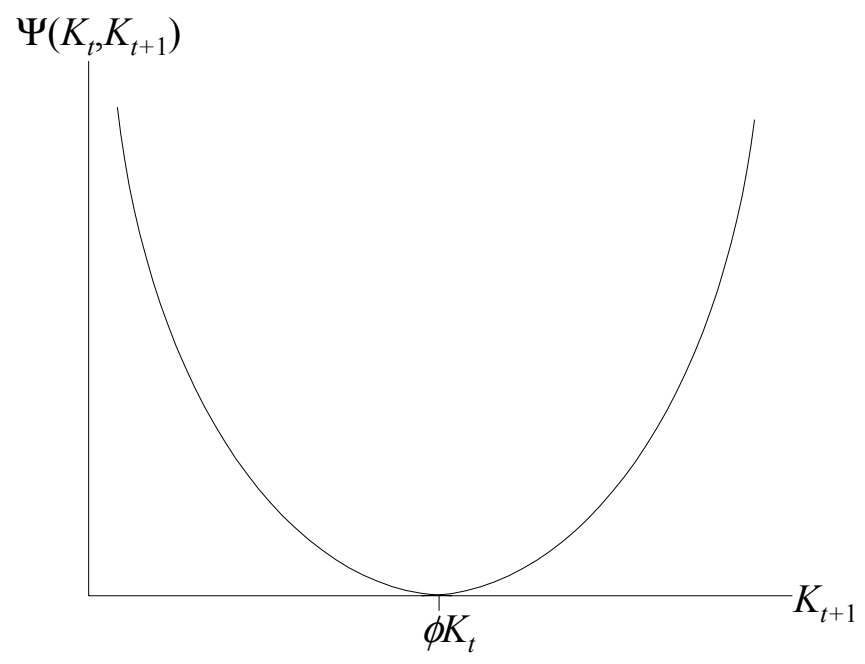

Figure 1: Adjustment Cost Function

As shown in Figure 1, the parameter $\phi$ separates values of $\frac{K_{t+1}}{K_{t}}$ for which the marginal adjustment cost, $\Psi_{2}\left(K_{t}, K_{t+1}\right)$, is negative from values for which the marginal adjustment cost is positive. Specfically, if $\frac{K_{t+1}}{K_{t}}<\phi$, then the marginal adjustment cost is negative; if $\frac{K_{t+1}}{K_{t}}>\phi$, then the marginal adjustment cost is positive. A feature of the Baxter-Crucini-Jermann assumption that $\phi=G_{K}$ is that if $G_{K}>1$, then $\phi>1$ and the marginal adjustment cost, $\Psi_{2}$, is negative for small positive rates of net investment satisfying $1<\frac{K_{t+1}}{K_{t}}<\phi$.

Let $q_{t}$ be the price of capital to be carried into period $t+1$, measured as the number of units of consumption that must be given up in period $t$ to

nous in investment and the capital stock in continuous time (and thus would be linearly homogeneous in $K_{t}$ and $K_{t+1}$ in a discrete-time version). In that specification, the convex adjustment cost is zero when net investment is zero. (In their framework, the depreciation rate is zero, so net and gross investment are equal. In terms of the notation in the current paper, that specification has $\phi=1$.) 
increase $K_{t+1}$ by one unit. Equation (1) implies that

$$
q_{t}=-J_{2}\left(K_{t}, K_{t+1}, A_{t} N_{t}\right) .
$$

The gross rate of return on capital carried from period $t$ to period $t+1$, $R_{t+1}$, is the ratio of the marginal product of capital (inclusive of any marginal effect of capital on adjustment costs) in period $t+1, J_{1}\left(K_{t+1}, K_{t+2}, A_{t+1} N_{t+1}\right)$, to the price of a unit of capital at the end of period $t, q_{t}$. Thus,

$$
R_{t+1} \equiv \frac{J_{1}\left(K_{t+1}, K_{t+2}, A_{t+1} N_{t+1}\right)}{q_{t}}=-\frac{J_{1}\left(K_{t+1}, K_{t+2}, A_{t+1} N_{t+1}\right)}{J_{2}\left(K_{t}, K_{t+1}, A_{t} N_{t}\right)} .
$$

\section{Constant Growth Paths}

I will analyze paths of the economy in which the effective amount of labor, $A_{t} N_{t}$, grows at a constant rate. Let $G_{N} \equiv \frac{N_{t+1}}{N_{t}} \geq 1$ be the constant gross growth rate of labor and let $G_{A} \equiv \frac{A_{t+1}}{A_{t}} \geq 1$ be the constant gross growth rate of the index of labor-augmenting technical progress, $A_{t}$.

I will focus attention on two types of growth paths, which I now define.

Definition 1 A constant growth path is a sequence $\left\{C_{t+j}, K_{t+j}\right\}_{j=0}^{\infty}$ such that $\frac{C_{t+j+1}}{C_{t+j}}=\frac{K_{t+j+1}}{K_{t+j}}=G_{K}$, where $G_{K}$ is a positive constant.

Definition 2 A neoclassical balanced growth path is a sequence $\left\{C_{t+j}, K_{t+j}, A_{t+j} N_{t+j}\right\}_{j=0}^{\infty}$ such that consumption per effective unit of labor, $c_{t+j} \equiv \frac{C_{t+j}}{A_{t+j} N_{t+j}}$, and capital per effective unit of labor, $k_{t+j} \equiv \frac{K_{t+j}}{A_{t+j} N_{t+j}}$, are constant.

Because $A_{t} N_{t}$ grows at a constant rate, all neoclassical balanced growth paths are constant growth paths. However, I will examine a class of constant growth paths that are not neoclassical balanced growth paths. In particular, in subsection 4.2, I will study constant growth paths in $A K$ models, where $J_{3} \equiv 0$.

Lemma $1 J_{i}\left(K_{t}, K_{t+1}, A_{t} N_{t}\right), i=1,2,3$, are constant along constant growth paths with $J_{3} \equiv 0$ and along neoclassical balanced growth paths. 
Proof. Since $J\left(K_{t}, K_{t+1}, A_{t} N_{t}\right)$ is homogenous of degree one in $K_{t}, K_{t+1}$, and $A_{t} N_{t}, J_{i}\left(K_{t}, K_{t+1}, A_{t} N_{t}\right), i=1,2,3$, is homogeneous of degree zero in $K_{t}, K_{t+1}$, and $A_{t} N_{t}$. Therefore, $J_{i}\left(K_{t}, K_{t+1}, A_{t} N_{t}\right)=J_{i}\left(1, \frac{K_{t+1}}{K_{t}}, \frac{A_{t} N_{t}}{K_{t}}\right)$, $i=1,2,3$, which is constant along constant growth paths with $J_{3} \equiv 0$. Alternatively, $J_{i}\left(K_{t}, K_{t+1}, A_{t} N_{t}\right)=J_{i}\left(\frac{K_{t}}{A_{t} N_{t}}, \frac{K_{t+1}}{A_{t} N_{t}}, 1\right)=J_{i}\left(k_{t}, G_{A} G_{N} k_{t+1}, 1\right)$, $i=1,2,3$, which is constant along neoclassical balanced growth paths.

Lemma 1, together with equations (3) and (4) immediately yields the following corollary.

Corollary $1 q_{t}$ and $R_{t+1}$ are constant along constant growth paths with $J_{3} \equiv$ 0 and along neoclassical balanced growth paths.

Now consider the relationship between aggregate consumption and the return on capital. Because $J\left(K_{t}, K_{t+1}, A_{t} N_{t}\right)$ is homogenous of degree one in $K_{t}, K_{t+1}$, and $A_{t} N_{t}$, Euler's Theorem and Lemma 1 imply that along constant growth paths with $J_{3} \equiv 0$ and along neoclassical balanced growth paths,

$$
C_{t}=J_{1} K_{t}+J_{2} K_{t+1}+J_{3} A_{t} N_{t}
$$

where $J_{i}$ denotes the constant value of $J_{i}\left(K_{t}, K_{t+1}, A_{t} N_{t}\right)$.

Let $W_{t} \equiv J_{3} A_{t} N_{t}$. Since $J_{3}$ is the marginal product of a unit of effective labor, $J_{3} A_{t} N_{t}$ is the total wage income in a neoclassical competitive economy.

Proposition 1 Along constant growth paths with $J_{3} \equiv 0$ and along neoclassical balanced growth paths, $C_{t}=W_{t}+\left(R-G_{K}\right) q K_{t}$.

Proof. Use the definition of $W_{t}$ and rewrite equation (5) as $C_{t}=$ $\left(-\frac{J_{1}}{J_{2}}-\frac{K_{t+1}}{K_{t}}\right)\left(-J_{2}\right) K_{t}+W_{t}=\left(R-G_{K}\right) q K_{t}+W_{t}$ where the second equality uses $q=-J_{2}$ and $R=-J_{1} / J_{2}$ from equations (3) and (4), respectively.

Proposition 1 shows that along neoclassical balanced growth paths in competitive economies, aggregate consumption exceeds aggregate wage income by the product of the excess of the rate of return over the growth rate of capital, $R-G_{K}$, and the value of the capital stock, $q K_{t}$. Equivalently, consumption equals wage income, $W_{t}$, plus capital income, $R q K_{t}$, less $G_{K} q K_{t}$, which is the value of resources needed to allow the capital stock to grow at rate $G_{K}$. 


\section{Intertemporal Optimization and the Mod- ified Golden Rule}

Beginning in this section, I will focus on constant growth paths that arise as the outcome of intertemporal optimization by a social planner. In the absence of externalities, the intertemporal allocation of consumption and capital accumulation chosen by a social planner is identical to the allocation in a competitive economy with a representative consumer. ${ }^{7,8}$ Analysis of the social planner's problem allows direct examination of the Golden Rule and Modified Golden Rule in the presence of convex adjustment costs.

Suppose that a social planner maximizes the social welfare function

$$
U_{t}=\frac{1}{1-\alpha} \sum_{j=0}^{\infty} \beta^{j}\left(\frac{C_{t+j}}{N_{t+j}}\right)^{1-\alpha}
$$

where $\frac{C_{t}}{N_{t}}$ is per capita consumption at time $t, \alpha>0$, and $\beta>0$. The social discount rate is $\rho \equiv \beta^{-1}-1$.

To keep the sum in equation (6) finite along constant growth paths, assume that the following condition holds. ${ }^{9}$

Condition 1 (Finite Utility) $\beta\left(\frac{G_{K}}{G_{N}}\right)^{1-\alpha}<1$.

To maximize the social welfare function in equation (6) subject to the constraint imposed by the production possibilities frontier in equation (1), substitute equation (1) into equation (6), differentiate with respect to $K_{t+j}$

\footnotetext{
${ }^{7}$ The equivalence of the allocation chosen by a social planner and the allocation in a competitive equilibrium is a widely-used device. In the presence of convex adjustment costs, Lucas and Prescott (1971) show that the equilibrium of a competitive industry is equivalent to the maximization of a particular consumer surplus. In a general equilibrium model with convex adjustment costs, Abel and Blanchard (1983) demonstrate that the competitive allocation is equivalent to that chosen by a social planner to maximize the utility of a representative consumer.

${ }^{8} \mathrm{I}$ analyze $A K$ models in subsection 4.2. Some $A K$ models are based on externalities, and the competitive outcome in those models is not identical to that chosen by a social planner.

${ }^{9}$ Along neoclassical balanced growth paths $G_{K}=G_{A} G_{N}$, so Condition 1 (Finite Utility) can be expressed in terms of exogenous parameters as $\beta G_{A}^{1-\alpha}<1$. In endogenous growth models, the growth rate of the capital stock, $G_{K}$, is endogenous, and Condition 1 (Finite Utility) must be verified when the equilibrium value of $G_{K}$ is determined.
} 
for $j>0$, set the derivative equal to zero, and evaluate the expression along a constant growth path to obtain

$$
\beta\left(\frac{C_{t+j}}{N_{t+j}}\right)^{-\alpha} \frac{1}{N_{t+j}} J_{1}=-\left(\frac{C_{t+j-1}}{N_{t+j-1}}\right)^{-\alpha} \frac{1}{N_{t+j-1}} J_{2} .
$$

Along constant growth paths, the growth rate of aggregate consumption equals the growth rate of the aggregate capital stock, $G_{K}$. Therefore, equation (7), along with the definition of $R_{t+1}$ in equation (4), implies

Proposition 2 (Modified Golden Rule) Along constant growth paths that maximize (6), $R=\beta^{-1} G_{K}^{\alpha} G_{N}^{1-\alpha}$, in the presence or absence of convex costs of adjustment.

Proof. Equation (7) implies $\beta\left(\frac{G_{C}}{G_{N}}\right)^{-\alpha} \frac{1}{G_{N}} J_{1}=-J_{2}$ where $G_{C}=\frac{C_{t+j}}{C_{t+j-1}}$ along a constant growth path. Since $G_{C}=G_{K}$ and $R=-J_{1} / J_{2}$, it follows that $R=\beta^{-1} G_{K}^{\alpha} G_{N}^{1-\alpha}$.

Proposition 2 is the familiar Modified Golden Rule, though in a somewhat unfamiliar form. The following corollary, which uses the fact that $G_{K}=$ $G_{A} G_{N}$ along neoclassical balanced growth paths, is an invariance result.

Corollary 2 Along neoclassical balanced growth paths that maximize (6), $R=\beta^{-1} G_{A}^{\alpha} G_{N}$, in the presence or absence of costs of adjustment.

Corollary 2 implies that the rate of return to capital along a neoclassical balanced growth path that maximizes (6) is invariant to the introduction of convex adjustment costs. Since the social planner's allocation is equivalent to a competitive allocation, this invariance result applies to competitive equilibria as well: the competitive rate of return along a neoclassical balanced growth path is invariant to the introduction of convex adjustment costs. Abel and Blanchard (1983, p. 678) suggested a need to adopt a "modified 'modified golden rule'" in the presence of convex adjustments in neoclassical growth models because they focussed on the marginal product of capital rather than on the rate of return on capital. However, Proposition 2 shows that the characterization of the Modified Golden Rule in terms of the rate of return is invariant to the introduction of convex adjustment costs.

Proposition 2 implies that along constant growth paths that maximize (6),

$$
R-G_{K}=\left(\beta^{-1}\left(\frac{G_{K}}{G_{N}}\right)^{\alpha-1}-1\right) G_{K}
$$


Equation (8) and Condition 1 lead to the following corollary to Proposition 2 .

Corollary 3 Along constant growth paths that maximize (6), $R>G_{K}$.

Corollary 2, along with the fact that the discount rate $\rho$ equals $\beta^{-1}-1$, leads to the following corollary to Proposition 1.

Corollary 4 If $G_{A} \equiv 1$, then along neoclassical balanced growth paths that maximize (6), $\beta R=G_{K}=G_{N}$ and $C_{t}=W_{t}+\rho G_{K} q K_{t}$, even in the presence of convex costs of adjustment.

If the index of labor-augmenting technical progress, $A_{t}$, is constant, then a neoclassical balanced growth path is a steady state with constant values of $\frac{K_{t}}{N_{t}}$ and $\frac{C_{t}}{N_{t}}$, so that $G_{K}=G_{N}$. The Golden Rule is the steady state that maximizes consumption per capita, $\frac{C_{t}}{N_{t}}$. Formally, the Golden Rule can be obtained from Corollary 4 by setting $\beta=1$ and $G_{K}=G_{N}$ to obtain ${ }^{10}$

Corollary 5 If $G_{A} \equiv 1$, then in the Golden Rule steady state of a neoclassical growth model, $R=G_{K}=G_{N}$ and $C_{t}=W_{t}$, even in the presence of convex costs of adjustment.

Corollary 5 generalizes to the case of convex adjustment costs the celebrated characterization of the Golden Rule derived by Phelps (1965), in which the rate of return is equal to the growth rate. Although the inclusion of adjustment costs does not alter this characterization of the Golden Rule, the Golden Rule value of the capital-labor ratio $k$ is generally altered by adjustment costs, as I show in Section 4.1. Corollary 5 also generalizes to the case of convex adjustment costs the results of Phelps $(1961,1965)$ and Swan (1964) who showed that in the Golden Rule steady state of a neoclassical competitive economy, investment equals capital income; equivalently, consumption equals wage income.

\footnotetext{
${ }^{10}$ Setting $\beta=1$ and $G_{K}=G_{N}$ violates Condition 1 (Finite Utility). The Golden Rule can be derived directly by noting that in a steady state (with $A_{t}$ normalized to equal one) $\frac{C_{t}}{N_{t}}=J\left(k, G_{K} k, 1\right)$. Maximizing $\frac{C_{t}}{N_{t}}$ with respect to $k$ yields $J_{1}+G_{K} J_{2}=0$. Therefore, in the Golden Rule, $R=-J_{1} / J_{2}=G_{K}$.
} 


\section{The Effect of Convex Adjustment Costs on Capital Accumulation}

It is convenient to analyze the introduction of convex adjustment costs in a framework in which the convex adjustment costs are additively separable from the production function, as in equation (2). Because the adjustment cost function $\Psi\left(K_{t}, K_{t+1}\right)$ is linearly homogeneous in $K_{t}$ and $K_{t+1}$, equation (2) can be rewritten as

$$
J\left(K_{t}, K_{t+1}, A_{t} N_{t}\right) \equiv F\left(K_{t}, A_{t} N_{t}\right)-\left[K_{t+1}-(1-\delta) K_{t}+K_{t} \psi\left(\frac{K_{t+1}}{K_{t}}\right)\right]
$$

where $\psi\left(\frac{K_{t+1}}{K_{t}}\right) \equiv \Psi\left(1, \frac{K_{t+1}}{K_{t}}\right)$ with the following properties: $\psi \geq 0, \psi(\phi)=$ 0 , and $\psi^{\prime \prime}>0$.

Along constant growth paths with $J_{3} \equiv 0$ and along neoclassical balanced growth paths, $\frac{K_{t+1}}{K_{t}}=G_{K}$ and (from Lemma 1) $J_{1}\left(K_{t}, K_{t+1}, A_{t} N_{t}\right.$ ) and $J_{2}\left(K_{t}, K_{t+1}, A_{t} N_{t}\right)$ are constant. Along these paths, with the additively separable adjustment costs in equation (9),

$$
J_{1}=F_{K}+1-\delta-\psi\left(G_{K}\right)+G_{K} \psi^{\prime}\left(G_{K}\right)
$$

and

$$
J_{2}=-1-\psi^{\prime}\left(G_{K}\right)
$$

where $F_{K}$ is the partial derivative of $F\left(K_{t}, A_{t} N_{t}\right)$ with respect to $K_{t}$. Recall from equation (4) that

$$
-R J_{2}=J_{1} .
$$

Substituting equations (10) and (11) into equation (12) and rearranging yields

$$
R=F_{K}+1-\delta-\psi\left(G_{K}\right)-\left(R-G_{K}\right) \psi^{\prime}\left(G_{K}\right) .
$$

\subsection{Neoclassical Growth Models}

In a neoclassical growth model, the production function $F\left(K_{t}, A_{t} N_{t}\right)$ is strictly increasing, concave, and linearly homogeneous in capital, $K_{t}$, and effective labor, $A_{t} N_{t}$. This production function can be expressed in intensive form as $A_{t} N_{t} f\left(k_{t}\right)$, where $f^{\prime}>0$ and $f^{\prime \prime}<0$. The marginal product of capital, $F_{K}\left(K_{t}, A_{t} N_{t}\right)$, is $f^{\prime}\left(k_{t}\right)$, so equation (13) can be written as 


$$
f^{\prime}(k)=R-1+\delta+\psi\left(G_{K}\right)+\left(R-G_{K}\right) \psi^{\prime}\left(G_{K}\right) .
$$

Along neoclassical balanced growth paths that maximize equation (6), the rate of return $R$ is invariant to the introduction of convex adjustment costs (Corollary 2). Therefore, equation (14) implies the following proposition.

Proposition 3 If $\phi<G_{A} G_{N}$, then the introduction of convex adjustment costs reduces $k$ along neoclassical balanced growth paths that maximize (6).

Proof. In the absence of adjustment costs, $f^{\prime}(k)=R-1+\delta$. Corollary 3 implies $R-G_{K}>0$. Since $G_{K}=G_{A} G_{N}$, the assumption that $\phi<$ $G_{A} G_{N}$ implies that $\phi<G_{K}$ and hence that $\psi\left(G_{K}\right)>0$ and $\psi^{\prime}\left(G_{K}\right)>0$. Therefore, $\psi\left(G_{K}\right)+\left(R-G_{K}\right) \psi^{\prime}\left(G_{K}\right)>0$, and equation (14) implies that the introduction of convex adjustment costs increases $f^{\prime}(k)$. Since $f^{\prime}()$ is strictly decreasing, the introduction of convex adjustment costs reduces $k$.

Corollary 6 If $\phi=G_{A} G_{N}$, then the introduction of convex adjustment costs does not affect the capital-labor ratio $k$ along neoclassical balanced growth paths that maximize (6).

Proposition 3 states that, consistent with Abel and Blanchard (1983) in which $\phi=1-\delta<G_{K}$, the introduction of convex adjustment costs reduces the capital-labor ratio along neoclassical balanced growth paths. Indeed, for any $\phi<G_{K}$, the introduction of convex adjustment costs reduces the capital-labor ratio along neoclassical balanced growth paths. However, if $\phi=G_{K}$, as in Baxter and Crucini (1993), Baxter and Jermann (1999), and Jermann (1998), then, according to Corollary 6, the capital-labor ratio along the balanced growth path that maximixes (6) is invariant to the introduction of convex adjustment costs. Indeed, it was this invariance that motivated these papers to assume that $\phi=G_{K}$.

\subsection{AK Models}

In this subsection I introduce convex costs of adjustment into an endogenous growth model of the $A K$ variety. I demonstrate that the invariance of the Modified Golden Rule rate of return to convex adjustment costs does not hold in $A K$ models. Although the Modified Golden Rule relationship between $R$ and $G_{K}$ is invariant to convex adjustment costs, I show that introducing 
convex adjustment costs in an $A K$ model reduces the growth rate of the capital stock and reduces the rate of return in the Modified Golden Rule.

Consider an $A K$ model with additively separable convex costs of adjustment. In this case, the aggregate production function $F\left(K_{t}, A_{t} N_{t}\right)$ in equation (9) is simply $A K_{t}$, where $A>0$ is a positive constant (so $G_{A}=1$ ). I want to retain the flexibility to accommodate two alternative interpretations of the $A K$ model. In the first interpretation, the production function $Y_{t}=A K_{t}$ is taken literally. With this literal interpretation, the social marginal product of capital and the private marginal product of capital are both equal to $A$. In addition, the marginal product of labor is zero, so that the amount of labor, $N_{t}$, does not affect the amount of output produced. However, $N_{t}$ also represents the number of consumers and thus $N_{t}$ affects consumption per capita, $C_{t} / N_{t}$. I retain the flexibility to analyze a growing population of consumers by allowing $G_{N}$ to exceed one.

The second interpretation, which is both more common and more plausible, is that the production function $Y_{t}=A K_{t}$ represents aggregate production in an economy with externalities in production. The externalities undermine the equivalence between the social planner's problem and the competitive equilibrium in an economy with a representative consumer. In the presence of externalities, the social marginal product of capital is $A$, but the private marginal product of capital is typically smaller than $A$. When $\mathrm{I}$ refer to the marginal product of capital (or rate of return), I will mean the social marginal product of capital (or social rate of return). Typically, $A K$ models based on production externalities have a constant number of workers, so $G_{N}$ would be equal to one.

To maintain the flexibility to accommodate both interpretations of the $A K$ model, I will focus on the social planner's decision problem. The social marginal product of capital equals $A$ under both interpretations, and I will let $G_{N}$ represent the growth rate of the population and the labor force, with the understanding that in the second interpretation (based on externalities), $G_{N}$ is typically equal to one.

Now consider an $A K$ model without convex adjustment costs. Let $\widehat{R}$ be the rate of return and $\widehat{G_{K}}$ be the growth rate of the capital stock along a constant growth path in an $A K$ model in the absence of convex adjustment costs. Since $F_{K}=A$ in the $A K$ model, the rate of return in the absence of convex adjustment costs is

$$
\widehat{R} \equiv A+1-\delta
$$


I will treat $\widehat{R}$ as a parameter, and I will assume that $\widehat{R}>\phi$.

To ensure that the sum in the social welfare function in equation (6) is finite in the absence of adjustment costs and that $\widehat{G_{K}}$ is greater than $\phi$ (see Lemma 2 below), assume that the following condition holds.

Condition 2 (Permissible Values of $\beta$ in AK Model) $\left(\frac{\phi}{R}\right)^{\alpha}<\beta\left(\frac{\widehat{R}}{G_{N}}\right)^{1-\alpha}<$ 1.

Provided that the exogenous value of the parameter $\widehat{R}$ exceeds $\phi$, the range of permissible values for $\beta\left(\frac{\widehat{R}}{G_{N}}\right)^{1-\alpha}$ in Condition 2 is non-empty. For given values of $\widehat{R}, G_{N}$, and $\alpha$, Condition 2 can be satisfied by appropriate choice of $\beta$.

Proposition 2 describes the Modified Golden Rule relationship between the rate of return and the growth rate of the capital stock along constant growth paths that maximize (6). This relationship holds for the $A K$ model, and in the absence of convex adjustment costs it can be written as

$$
\widehat{R}=\beta^{-1}{\widehat{G_{K}}}^{\alpha} G_{N}^{1-\alpha} .
$$

Lemma 2 If Condition 2 (Permissible Values of $\beta$ in AK Model) holds, then along constant growth paths that maximize (6) in an AK model

(a) Condition 1 (Finite Utility) holds in the absence of adjustment costs, i.e., $\beta\left(\frac{\widehat{G_{K}}}{G_{N}}\right)^{1-\alpha}<1$;

(b) $\phi<\widehat{G_{K}}<\widehat{R}$.

Proof. (a) Equation (16) implies that $\left(\frac{\widehat{G_{K}}}{G_{N}}\right)^{\alpha}=\beta \frac{\widehat{R}}{G_{N}}$ so that $\beta\left(\frac{\widehat{G_{K}}}{G_{N}}\right)^{1-\alpha}=$ $\beta\left(\beta \frac{\widehat{R}}{G_{N}}\right)^{\frac{1-\alpha}{\alpha}}=\left(\beta\left(\frac{\widehat{R}}{G_{N}}\right)^{1-\alpha}\right)^{\frac{1}{\alpha}}<1$, where the inequality follows from Condition 2 .

(b) If Cndition 2 holds, then equation (16) implies $\left(\frac{\phi}{G_{K}}\right)^{\alpha}<\beta \widehat{R}_{N}^{\alpha-1}{\widehat{G_{K}}}^{-\alpha}=$ 1 so $\phi<\widehat{G_{K}}$. Equation (16) implies $\frac{\widehat{G_{K}}}{\widehat{R}}=\beta\left(\frac{\widehat{G_{K}}}{G_{N}}\right)^{1-\alpha}<1$, where the inequality follows from part (a). Therefore $\widehat{G_{K}}<\widehat{R}$.

Along constant growth paths that maximize (6) in an $A K$ model, the rate of return, $R$, and the growth rate of capital, $G_{K}$, are endogenous variables 


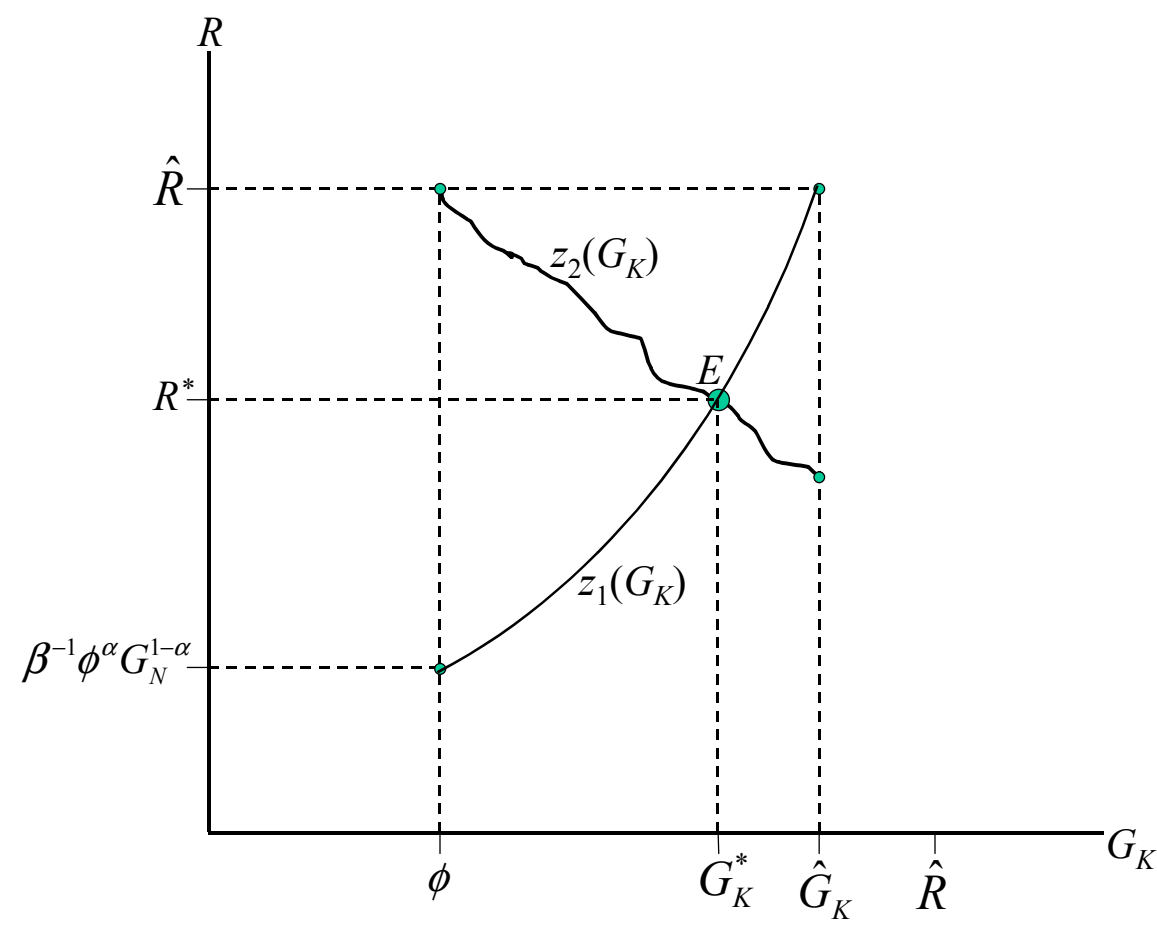

Figure 2: $R$ and $G_{K}$ in the $A K$ Model with Convex Adjustment Costs

that are jointly determined by the Modified Golden Rule relationship in Proposition 2 and by the expression for the rate of return in equation (13). The Modified Golden Rule relationship can be written as

$$
R=z_{1}\left(G_{K}\right) \equiv \beta^{-1} G_{K}^{\alpha} G_{N}^{1-\alpha}
$$

The function $z_{1}\left(G_{K}\right)$ is strictly increasing and, since $\phi<\widehat{G_{K}}$,

$$
z_{1}(\phi)=\beta^{-1} \phi^{\alpha} G_{N}^{1-\alpha}<z_{1}\left(\widehat{G_{K}}\right)=\widehat{R} .
$$

Figure 2 shows $z_{1}\left(G_{K}\right)$ as an upward-sloping curve ${ }^{11}$ for $\phi \leq G_{K} \leq \widehat{G_{K}}$.

In an $A K$ model, equation (13) can be rewritten using $F_{K}=A$ and the

\footnotetext{
${ }^{11}$ The elasticity of $z_{1}\left(G_{K}\right)$ with respect to $G_{K}$ is constant and equal to $\alpha>0$. Figure 2 is drawn for $\alpha>1$, so $z_{1}\left(G_{K}\right)$ is a convex function of $G_{K}$.
} 
definition of $\widehat{R}$ in equation (15) to obtain

$$
R=z_{2}\left(G_{K}\right)=\frac{\widehat{R}-\psi\left(G_{K}\right)+G_{K} \psi^{\prime}\left(G_{K}\right)}{1+\psi^{\prime}\left(G_{K}\right)} .
$$

Observe that $z_{2}(\phi)=\widehat{R}$. Lemma 3 below states that $z_{2}\left(G_{K}\right)$ slopes downward for $\phi \leq G_{K} \leq \widehat{G_{K}}$, as shown in Figure 2, provided that adjustment costs are not too large. The following condition provides an upper bound the size of adjustment costs.

Condition 3 (Adjustment Costs Not Too Large) $0<\psi\left(\widehat{G_{K}}\right)<\widehat{R}-\widehat{G_{K}}$.

Lemma 2 implies if Condition 2 (Permissible Values of $\beta$ in $A K$ Model) holds, then $\widehat{R}-\widehat{G_{K}}>0$ so that the range of admissible values for $\psi\left(\widehat{G_{K}}\right)$ in Condition 3 is not vacuous.

Lemma 3 If Condition 2 (Permissible Values of $\beta$ in AK Model) and Condition 3 (Adjustment Costs Not Too Large) hold, then in the presence of strictly convex adjustment costs $\left(\psi^{\prime \prime}>0\right)$

(a) $z_{2}^{\prime}\left(G_{K}\right)<0$ for $\phi \leq G_{K} \leq \widehat{G_{K}}$

(b) $z_{2}\left(\widehat{G_{K}}\right)<\widehat{R}$.

Proof. (a) Differentiate $z_{2}\left(G_{K}\right)$ defined in equation (19) to obtain $z_{2}^{\prime}\left(G_{K}\right)=$ $-\frac{\psi^{\prime \prime}\left(G_{K}\right)}{\left[1+\psi^{\prime}\left(G_{K}\right)\right]^{2}}\left(\widehat{R}-G_{K}-\psi\left(G_{K}\right)\right)$. Condition 3 implies that $\widehat{R}>\widehat{G_{K}}+$ $\psi\left(\widehat{G_{K}}\right) \geq G_{K}+\psi\left(G_{K}\right)>0$ for $\phi \leq G_{K} \leq \widehat{G_{K}}$. Therefore, $z_{2}^{\prime}\left(G_{K}\right)<0$ for $\phi \leq G_{K} \leq \widehat{G_{K}} . \quad(b)$ Use $z_{2}(\phi)=\widehat{R}, \phi<\widehat{G_{K}}$ (from Lemma 2), and part $(a)$ to conclude that $z_{2}\left(\widehat{G_{K}}\right)<\widehat{R}$.

Let $G_{K}^{*}$ and $R^{*}$ be the values of $G_{K}$ and $R$, respectively, along a constant growth path that maximizes (6) in an $A K$ model with convex adjustment costs. Point $E$ in Figure 2 represents $G_{K}^{*}$ and $R^{*}$. Inspection of Figure 2 proves the following proposition. ${ }^{12}$

\footnotetext{
${ }^{12}$ The following features of Figure 2 are sufficient to prove that there exists a unique $G_{K}$ in $\left(\phi, \widehat{G_{K}}\right)$ such that $z_{1}\left(G_{K}\right)=z_{2}\left(G_{K}\right)$ : For $\phi \leq G_{K} \leq \widehat{G_{K}}, z_{1}\left(G_{K}\right)$ is continuous and increasing; $z_{2}\left(G_{K}\right)$ is continuous and decreasing; $z_{1}(\phi)<z_{2}(\phi)=\widehat{R}$; and $z_{1}\left(\widehat{G_{K}}\right)=$ $\widehat{R}>z_{2}\left(\widehat{G_{K}}\right)$.
} 
Proposition 4 If Condition 2 (Permissible Values of $\beta$ in AK Model) and Condition 3 (Adjustment Costs Not Too Large) hold, then $\phi<G_{K}^{*}<\widehat{G_{K}}$ and $R^{*}<\widehat{R}$.

Proposition 4 indicates that the introduction of convex adjustment costs in an $A K$ model reduces the growth rate of capital and the rate of return along constant growth paths that maximize (6). Though the invariance of the Modified Golden Rule rate of return that holds in the neoclassical growth model does not hold in the $A K$ model, the Modified Golden Rule relationship between $G_{K}$ and $R$ (which is represented in Figure 2 by $z_{1}\left(G_{K}\right)$ ) is invariant to the introduction of convex adjustment costs in the $A K$ model, as well as in the neoclassical growth model. In the neoclassical growth model, however, $G_{K}$ is invariant to the introduction of convex adjustment costs, so the Modified Golden Rule relationship implies that $R$ is invariant to the introduction of convex adjustment costs. However, in an $A K$ model, the introduction of convex adjustment costs reduces $G_{K}$, and the Modified Golden Rule relationship implies that $R$ must move in the same direction as $G_{K}$, when comparing balanced growth paths that maximize the social welfare function in equation (6).

\section{Conclusion}

In this paper I have shown that the Modified Golden Rule relationship, $R=z_{1}\left(G_{K}\right)$ in equation (17), is invariant to the introduction of convex adjustment costs. The economic factors underlying this invariance are very powerful. A standard condition in intertemporal optimization, often called the intertemporal Euler condition, is that the product of a (gross) rate of return and the intertemporal marginal rate of substitution equals one. For a social planner maximizing the social welfare function in equation (6), the rate of return is $\frac{R}{G_{N}}$ because a unit of aggregate consumption sacrificed today will increase aggregate consumption in the subsequent period by $R$ units, but the consumption must be spread among $G_{N}$ times as many people. The intertemporal marginal rate of substitution is $\beta\left(\frac{G_{C}}{G_{N}}\right)^{-\alpha}$, so the intertemporal Euler condition is $\frac{R}{G_{N}} \beta\left(\frac{G_{C}}{G_{N}}\right)^{-\alpha}=1$. Since $G_{C}=G_{K}$ along constant growth paths, this Euler condition can be rewritten as $R=\beta^{-1} G_{K}^{\alpha} G_{N}^{1-\alpha}$, which is the Modified Golden Rule relationship, $R=z_{1}\left(G_{K}\right)$. I have demonstrated that 
this relationship is invariant to the introduction of convex adjustment costs. More generally, it is independent of the entire production-cum-adjustmentcost technology.

Though the Modified Golden Rule relationship, $R=z_{1}\left(G_{K}\right)$, is independent of the specification of technology, the Modified Golden Rule rate of return is not necessarily independent of technology. By focussing on costs of adjustment in this paper, I have demonstrated cases in which rate of return invariance holds and cases in which it does not hold. In neoclassical growth models, in which the long-run growth rates of capital and labor are exogenous, the invariance of the Modified Golden Rule relationship, $R=z_{1}\left(G_{K}\right)$, implies that the Modified Golden Rule rate of return, and, equivalently, the long-run rate of return in a competitive economy, are invariant to the introduction of adjustment costs. However, in endogenous growth models, convex adjustment costs reduce the long-run growth rate of capital, and thus reduce the Modified Golden Rule rate of return, $R=z_{1}\left(G_{K}\right)$, though the function $z_{1}\left(G_{K}\right)$ is invariant to adjustment costs. 


\section{References}

[1] Abel, Andrew B., "The Effects of a Baby Boom on Stock Prices and Capital Accumulation in the Presence of Social Security," mimeo, The Wharton School of the University of Pennsylvania, December 2000.

[2] Abel, Andrew B. and Olivier J. Blanchard, "An Intertemporal Model of Saving and Investment, Econometrica 51, 3 (May 1983), 675-692.

[3] Basu, Parantap, "An Adjustment Cost Model of Asset Pricing," International Economic Review, 28, 3 (October 1987), 609-621.

[4] Baxter, Marianne and Mario J. Crucini, "Explaining Saving-Investment Correlations," American Economic Review, 83, 3 (June 1993), 416-436.

[5] Baxter, Marianne and Urban J. Jermann, "Household Production and the Excess Sensitivity of Consumption to Current Income," American Economic Review, 89 (September 1999), 902-920.

[6] Blanchard, Olivier J. and Stanley Fischer, Lectures on Macroeconomics, Cambridge, MA: MIT Press, 1989.

[7] Gould, John P., "Adjustment Costs in the Theory of Investment of the Firm," Review of Economic Studies, 35 (January 1968), 47-55.

[8] Jermann, Urban J., "Asset Pricing in Production Economies," Journal of Monetary Economics, 41, 2 (April 1998), 257-275.

[9] Lucas, Robert E., Jr., "Adjustment Costs and the Theory of Supply," Journal of Political Economy, 75, 4 (August 1967), 321-334.

[10] Lucas, Robert E., Jr. and Edward C. Prescott, "Investment Under Uncertainty," Econometrica, 39, 5 (September, 1971), 659-681.

[11] Phelps, Edmund, "The Golden Rule of Accumulation: A Fable for Growthmen," American Economic Review, 51 (September 1961), 638643.

[12] Phelps, Edmund S., "Second Essay on the Golden Rule of Accumulation," American Economic Review, 55, 4 (September 1965), 793-814. 
[13] Swan, Trevor W., "Growth Models: Of Golden Ages and Production Functions," in Economic Development with Special Reference to East Asia, Proceedings of a conference held by the International Economic Association, New York: St. Martin's Press, 1964, 3-16.

[14] Treadway, Arthur B., "On Rational Entrepreneurial Behavior and the Demand for Investment," Review of Economic Studies, 36 (April 1969), 227-239. 